\title{
Going for the Gold: Prosecutorial Decision Making in Cases of Wife Assault
}

\author{
David Rauma \\ Department of Sociology, University of Michigan
}

Violence is a common feature of family life in the United States, but it has received little attention from the criminal justice system. Since women are the primary victims of such violence, some observers have argued that this inattention represents yet another form of discrimination against women, or is at least protective of traditional values concerning marriage and the family. For example, Martin (1976, p. 88) states "The sanctity of the family home pervades the world of law enforcement." In a similar vein, Roy $(1977$, p. 138) argues that "underlying the criminal justice system is the covert toleration of wifebeating, as indicated in the policy and personal attitudes of the police, prosecutors, and judges; and through the inefficient procedures which render even the existing legal remedies inadequate." These and similar criticisms generally treat the police, prosecutors, and judges as administrators of justice who, in cases of wife assault, fail to do their jobs.

One can see how a cycle of inattention could exist in the criminal justice system without resort to explanations based on misogynist individual attitudes or patriarchical organizational goals, or to claims of inefficiency and indolence. At the very least, police may be reluctant to arrest batterers or enforce court orders because of nonsupport from prosecutors and judges, and without the exercise of police discretion, cases of domestic violence cannot come to the attention of the courts. Under these circumstances, few cases would be prosecuted, thus further reinforcing

Thanks go to V. Lee Hamilton, Richard O. Lempert, and Russell Dobash for comments and suggestions, and to Nancy Blum for her skillful coding of the data. Special thanks go to Donileen R. Loseke for her help with the data and the data analyses, and for her comments on various drafts of the paper. An earlier version of this paper was presented at the 1983 meetings of the Law and Society Association, Denver, CO. Support for this research was provided by a grant from the National Institute of Mental Health, Center for the Study of Violent and Anti-social Behavior (Grant 1ROIMH34616-O1A1). Send requests for reprints to David Rauma, University of Michigan, 3012 Literature, Science \& Arts Building, Ann Arbor, MI 48109-1382. 
police disinterest (see Cole, 1970, for a general account of police-prosecutor relations, and Berk, Loseke, Berk, and Rauma, 1980, and Berk, Rauma, Loseke, and Berk, 1982, for an account related to domestic violence cases).

However, that is not necessarily the whole story. As Bittner (1980, p. 125) has pointed out, law enforcement-or the application of legal rules to particular situations-is something that the police do with a frequency "located somewhere between virtually never and very rarely." Instead, police handle situations as they come up, with the criminal code serving as a set of boundaries for appropriate action and, perhaps more importantly, as a later set of justifications for the actions that they have taken. Furthermore, Bittner suggests that police are seldom concerned with more than a fraction of defined offenses: those offenses for which it is clear that the offender needs to be caught and physical force will likely be necessary in order to do so. In line with this, Berk and Loseke (1980) have argued that police arrest decisions in cases of wife assault appear to be determined by the need to deal with the volatility of the immediate situation, especially the possibility of further violence (see also Worden and Pollitz, 1984). Discretionary decision making in instances of wife assault, seen by some as inefficiency or discrimination, is perhaps reflective more of police work generally than of incompetence or other, more sinister agendas.

Even if police are dealing with domestic violence in ways consistent with the rest of their work, there remains the possibility that prosecutors are a source of differential treatment for wife batterers. The statements cited earlier point to a pervasive attitude that prosecutors presumably share in. Certainly critics of plea bargaining (e.g., National Advisory Commission on Criminal Justice Standards and Goals, 1973) have claimed that prosecutors' negotiations with defendants amount to unnecessary leniency and undermine the entire judicial process. However, discussions of prosecutors' work bear striking similarities to descriptions of police work, and suggest that, given their authority to use discretion, prosecutors likewise deal with situations in which the legal code serves as both a delimiter and a resource. In this paper, I will examine how prosecutors make decisions, by analyzing data from one prosecutor's office in order to better understand how prosecution decisions are made in cases of wife assault.

In an attempt to address the problem of criminal justice system inattention to domestic violence, a unique project was developed in Santa Barbara, California. Funded largely by the Law Enforcement Assistance Agency (LEAA), the project had the goal of improving the attention to spousal abuse cases at various levels of the system. Among the various programs were educational efforts with the police, to increase their understanding 
of domestic violence generally and of the need to document such cases adequately, and a special effort within the District Attorney's office to divert certain offenders into counseling as an alternative to prosecution for spousal assault. The stated aim of the diversion program was simple: in cases normally classified by the District Attorney as less severe (e.g., misdemeanors) ${ }^{1}$ and when offenders had no prior record of assault, a criminal record and the possibility of jail time could be "exchanged" for attendance in a counseling program.

Earlier papers have discussed in detail the workings of the Santa Barbara Family Violence Program (Berk, Berk, and Loseke, 1979) and the efforts at changing the handling of domestic violence cases by the police and the District Attorney's office (Berk et al., 1980; Berk et al., 1982). Here, I will focus on the workings of the District Attorney's office during the height of the Family Violence Program (FVP), before LEAA funding was reduced, resulting in program reduction. Using a sample of 199 domestic incidents forwarded to the District Attorney's office during this time, I will look at the three initial steps toward prosecution: (1) the decision whether or not to follow up an incident (i.e., collect more information and evidence), (2) the decision whether or not to take a case to arraignment, and (3) the decision whether or not to use the diversion option, given that a case could be arraigned.

Specifically, the issues addressed in this paper are both substantive and methodological. First, I will consider what factors affected the decisionmaking process at each step, given a committed Deputy District Attorney (DDA) and a mandate to actively pursue family violence cases, but also given organizational requirements such as evidence and the formal criteria for diversion. Critics have raised the issue of inefficient and perhaps discriminatory behavior on the part of criminal justice officials in cases of wife assault. My aim is to first consider how decisions are made, and only later will I consider the possibility that the use of certain "extralegal" factors constitutes discriminatory behavior. For the analyses presented herein, I will not consider extra-legal to be "synonymous with 'illegal,' 'inappropriate,' or 'socially unjust' "' (Nagel, 1983, p. 482).

A second issue concerns whether or not the diversion program was used as designed. Informal evidence suggests not, and I will be able to formally investigate that stage in the process leading ultimately to prosecution.

Finally, I will be concerned with the issue of sample selection bias. The criminal justice system is typically described as a "funnel," where at each step additional cases are dropped, presumably in a systematic manner. The three decision steps make possible analysis strategies that

\footnotetext{
${ }^{1}$ Generally, I will use the terms serious/severe and not serious/not severe to refer to felonies and misdemeanors, respectively.
} 
explicitly take into account this funneling process and the sample selection problem that it presents. The problem and possible remedies will be discussed in detail later.

\section{THE DISTRICT ATTORNEY'S OFFICE}

\section{Background: The Family Violence Project}

In brief, the DA component of the Family Violence Project (FVP) had four goals: (1) to encourage the police to report all domestic violence cases that came to their attention, (2) to encourage the police to properly document those incidents in order to facilitate possible prosecution, (3) to increase the number of offenders sanctioned, and (4) to make available a form of diversion into counseling as an alternative for less serious incidents of violence (for a more complete description of the program, see Berk et al., 1979).

The FVP began operation in November 1978, with the assignment of a full-time DDA to the exclusive handling of domestic violence cases. With the help of a full-time criminal investigator, the DDA was to prosecute such cases more aggressively and to make use of a diversion option for less serious offenses. Educational efforts were also begun with the police, to instruct them in the proper documentation of domestic violence calls. The police were specifically encouraged to report such calls as domestic cases rather than, for example, disturbing the peace. The rationale was simple: with proper documentation, the DDA could in principle take further action leading to prosecution or diversion, and with support of their own actions through increased prosecutorial attention and action, the police would be further encouraged to take domestic calls seriously.

Using weekly time series data for the police and the District Attorney's office, other analyses have demonstrated how the FVP improved police reporting practices as well as increased the number of offenders held accountable by the District Attorney, at least while special attention was paid to making those changes work (Berk et al., 1980; Berk et al., 1982). Once that attention lagged, in part because LEAA funding was reduced and because of personnel turnover and reorganization in the District Attorney's office, the system effectively returned to its previous state (Berk et al., 1982).

\section{The Diversion Program}

According to the Santa Barbara County District Attorney's Family Violence Prosecution Manual, "The purpose of diversion is to hold offenders accountable for their conduct while allowing those who wish to prove themselves and avoid conviction the opportunity to attend counseling and educational sessions." The Santa Barbara program was intended as a legitimate alternative to prosecution for individuals who could be and 
ordinarily would be prosecuted. Therefore, the decision to divert was to be made after the decision was made to file charges against the suspect. Diversion could be allowed, at the prosecutor's discretion, under these circumstances:

1. the offender had never been convicted of a domestic violence offense,

2. the offender had no significant criminal record,

3. the injuries to the victim were not serious,

4. the offender seemed sufficiently responsible, indicating a reasonable likelihood of completing the diversion program,

5. the offender desired diversion, and

6. the victim had no reasonable objections to diversion.

A minimum of 1 year of participation in the diversion program was required, and it could be longer. If at the end of the diversion period, the offender had successfully completed the requirements of the counseling program and had been involved in no further violence against anyone, the original charges would be dismissed. If, however, at any time the offender did not participate in the program or commited some violent act, the case would be brought to court and prosecution would commence.

\section{The Process Leading to Diversion}

As noted above, the diversion step is the third decision made by the DDA, at least for cases that reach that level. At the first step, cases are forwarded to the District Attorney's office from police departments throughout Santa Barbara County. Documentation of these cases may take one of three forms: field cards, with minimal information reflecting minimal contact with citizens; incident reports (i.e., case sheets or offense reports), reflecting more prolonged contact and which are likely to contain more information than field cards; and arrest reports, which generally contain the greatest documentation of the incident.

Among the reports forwarded by the police, the DDA screens out cases for possible prosecution. Very often, a criminal investigator will be sent out to gather more information, in particular if there was no arrest and therefore only a field card or an incident report was filled out (ordinarily, because of the lack of information, incidents recorded on field cards are discarded by the DDA).

Once the DDA has decided to follow up a case, perhaps by collecting more information, the next decision is whether or not to arraign the offender (including what charges are to be filed, if any). Only after this decision, to arraign or not, is the decision made about possible diversion. The DDA may recommend diversion rather than prosecution. However, if the offender is unwilling to accept diversion, prosecution will proceed (it is also possible that the offender will be diverted after arraignment, but I will not be concerned with that outcome here). In principle, the steps leading to diversion differ from the diversion decision only in that 
the decision to divert is to be based solely on characteristics of the offender and the offense. Evidentiary matters have presumably already been considered.

The question that can now be raised concern what factors affect the sequential selection of cases? Of course there are legal requirements such as the strength of evidence, but the relevant literature on prosecutorial decision making suggests that other legal and "extra-legal" factors also play a role. There is also a good deal of anecdotal evidence that domestic violence cases are often not given serious consideration. In the next section I will explore these issues, as well as specify a model of how these decisions might be made.

\section{SPECIFYING A MODEL}

\section{Prosecutorial Decision Making}

With few exceptions, the handling of family violence by the criminal justice system has not been addressed in any systematic fashion. Evidence concerning the behavior of prosecutors and judges is largely anecdotal (e.g., Martin, 1976; Dobash and Dobash, 1979). For example, much is usually made of the fact that few domestic offenders are ever prosecuted, let alone convicted of assault or other personal violence crimes. However, it is equally true that few assault cases are prosecuted and prosecuted successfully. For instance, the Vera Institute study of felony arrests in New York City shows that "a defendant who enters the criminal process charged with a felony assault is less likely to be convicted than defendants entering the process on other felony charges" (Vera Institute of Justice, 1977, p. 24). Of the 369 felony assault cases in the Vera Institute sample, only $18 \%$ entered the criminal process, and of these cases, almost half were dismissed altogether. Only $10 \%$ of the original 369 cases were ever decided, and most by pleas to lesser charges than by trial. ${ }^{2}$ Without research explicitly comparing the processing of domestic violence offenses with that of other types of offenses, claims that domestic violence cases are treated in some systematically different fashion are merely claims.

But what factors are important in that decision making process? I will argue that one cannot simply assume that broad goals (such as the defense of patriarchy) or misogynist attitudes motivate the behavior of criminal justice actors. Rather, their actions must first be understood within the context of the organization they are a part of. Reiss (1971, pp. 114-120) suggests that the criminal justice system is a "loosely articulated hierarchy of . . . subsystems," and consequently that "each subsystem creates its own system of justice" [emphasis in original]. Within this view, overarching

${ }^{2}$ Of the 67 cases that went to court, $46 \%$ involved individuals with a prior relationship, and of these cases less than half could be called domestic incidents. However, the numbers are too small to make any generalizations from. 
goals such as the defense of the family home are virtually impossible to comprehend without an understanding of how those goals become articulated in the behavior of individual actors at various levels of the system. The Vera Institute findings are consistent with this view, that the criminal justice system is a loosely coupled system whose components respond to one another but which lacks a comprehensive set of rules and a single notion of justice (Reiss, 1971; Weick, 1976; Hagan, Hewitt, and Alwin, 1979). Analyses of the Family Violence Program generally suggest a similar story; without maintained vigilance, coordination between the police and the prosecutor can deteriorate rapidly (Berk et al., 1980; Berk et al., 1982).

Overall, there is a vast literature describing the processing of individuals through the criminal justice system: from studies of police discretion (e.g., Bittner, 1967, 1980; Johnson, Petersen, and Wells, 1977; S. F. Berk and Loseke, 1980; Grant, Grant, and Toch, 1982; Visher, 1983; Smith, 1984), decision making within the prosecutor's office (e.g., Hall, 1975; Williams, 1976; Heumann, 1977; Myers and Hagan, 1979; Stanko, 1982), to sentencing decisions (e.g., Hagan, Nagel, and Albonetti, 1980; Kleck, 1981; Brereton and Caspar, 1982; Wheeler, Weisburd, and Bode, 1982; Peterson and Hagan, 1984). Throughout this literature are references to various factors that, taken together, point to specific concerns underlying prosecutorial decisions that are similar to those described by Bittner as underlying police work.

That prosecutors are concerned with making good cases is a truism, but it is also an oversimplification. In the context of a bureaucratic organization, a variety of demands may be made on prosecutors: organizational requirements such as for quick and successful resolution of cases, as well as imperatives to satisfy legal prescripts, both procedural and evidentiary. Caseload pressures may prompt an increased concern for efficiency on the part of prosecutors, and both judges and the public may demand effectiveness, the former from a legal and an organizational perspective and the latter from a desire for "just desserts." While Heumann (1977) argues that caseload pressures have been exaggerated, especially in the higher courts, others such as Cole (1970) and Myers and Hagan (1979) have identified them as a real constraint on the efforts of prosecutors and as a real incentive to either drop cases or to plea bargain. Added to caseload pressures-resulting in part from the time needed to take a case to trial-are the risks of taking a case to trial, which affect both defense and prosecution attorneys. Guilty pleas to lesser charges may be a solution acceptable to all sides. As Newman $(1956$, p. 788 ) has pointed out 
such a bargain in that he was assured of a conviction, yet did not have to spend the time and effort to prepare a case trial. He also avoided the everpresent risk of losing even a clear-cut case should the accused have gone before a jury. The court, too, benefitted. Court calenders were, and are, crowded and the entire court system would admittedly be inadequate to cope with criminal trials should all, or even a fraction of the felony arrests decide to go to trial. This, coupled with the generally favorable attitude toward bargaining processes on the part of the lawyers, civil and criminal, in the local bar, made informal methods of conviction almost inevitable.

These pressures, whether inevitable or not, have produced much more informal means of deciding cases through the plea bargaining process. As Mather (1974) suggests, plea bargaining allows attorneys on both sides to emphasize mitigating circumstances that could ultimately affect sentencing but which would be inadmissable during a trial to decide guilt or innocence. Evidence remains crucial, of course, but weaknesses there can only add to the pressures to bargain. These mitigating or "extralegal" circumstances seem to center around the character of the defendant (including not only the past record, but the likely future behavior of the defendant as well), the seriousness of the offense, the appropriate punishment for that offense (and that offender), and the character of the victim. Underlying these considerations is an assumption that the defendant did something worthy of punishment, or at least worthy of attention by authorities; according to Sudnow (1964, p. 271) the defendant's guilt "is not attended to." Similar to police interventions, prosecutor intervention is apparently motivated by a perceived need to exercise their own legal solutions to particular situations. Whereas the police can use force when warranted, prosecutors can file charges and therefore make private troubles a matter of public concern (Myers and Hagan, 1979).

Character assessments appear to be crucial to prosecutors' decisions about further action. Littrell (1979), for example, gives accounts of how rap sheets can be used by prosecutors in order to construct a character profile for a defendant: is this person of "sinister" character? Character assessments can affect how serious the offense is deemed to be, whether the defendant is viewed as likely to do more of the same, or worse, and what the just desserts are. Stanko (1982) discusses the role of victim and the victim's character in prosecutors' decision making. Whether or not the victim can stand up in court and testify and be believed is crucial to the disposition of the case, especially in personal violence cases. Credibility is damaged if the victim is of suspect character, and may be quickly lost if the victim is seen as a willing or even an active participant in the offense. Sudnow's (1964) concept of a normal crime gets at the same process, but also includes various other elements such as offense seriousness, type of victim (and implicitly something about character), past and future misbehavior, and appropriate sanctions. Similar to the 
police, prosecutors appear to use their various options when those options seem the best or perhaps the only recourse.

Myers and Hagan (1979), in discussing how prosecutors assess cases, go further and suggest that typifications are used, based on general characteristics of what constitute good and bad cases. According to Myers and Hagan (1979, p. 440), good or "strong" cases are described in legally relevant terms because their strength lies in their ability to be successfully prosecuted. Victims who are likely to be good witnesses will be described in terms of their credibility as witnesses, rather than in terms of their credibility as victims. Thus, even extra-legal criteria are given a legal interpretation as a justification for relying on them. Unfortunately, "strong" cases are defined along a large number of dimensions, including those listed above, and are consequently seldom encountered. The typical or in Sudnow's terms, "normal" crime makes a bad case. Decisions about cases, particularly in the early stages, are decisions about allocating resources, and standards based on "strong case typifications" (Myers and Hagan, 1979, p. 440) allow prosecutors to make decisions about the likelihood of a successful conviction. If they are to be used efficiently, resources must be allocated to good cases, but also to bad cases, when such cases warrant attention.

Within this behavioral framework, one can begin to see how the processing of domestic violence cases could be seen by an observer as discriminatory. The lore surrounding such cases is that victims, who are often the only witnesses, are typically reluctant to cooperate with prosecutors. Injuries are difficult to document without a hospital report, and if there has been a history of violence, victims may be viewed by judges and juries as less credible for having remained in a violent relationship for any period of time. Given the expected low probability of conviction, the continued allocation of resources to such cases may be difficult to rationalize. Consider this statement by a Deputy District Attorney in Santa Barbara:

It's like I had ten pounds of gold and ten pounds of lead and could only take one of them. You take the gold. Domestics are like lead, other cases are like gold-they're easier, they don't take as much time, they're worth more.

Thus, one goal of the Santa Barbara Family Violence Project was to make an alchemist's dream come true.

\section{A Random Utility Approach to the Screening Process}

From these descriptions of prosecutor decision making, one can move to a random utility formulation in order to model screening decisions made within the prosecutor's office (Luce and Raiffa, 1957; Hey, 1979). The prosecutor's utility function will be maximized by selection of cases for further action that meet legal criteria for a good case (e.g., solid 
evidence), which have other desirable characteristics (e.g., a credible victim or witness who would be convincing to a judge and/or jury, or an offender "in need" of punishment), and which are of sufficient seriousness (e.g., the offender seriously injured the victim) to warrant prosecution. Put a bit differently, the systematic component of the utility function is composed of characteristics of the case that correspond to legal criteria, characteristics of the case that correspond to "extralegal" criteria, organizational requirements within the prosecutor's office, any other characteristics that might affect the case's later disposition, and offenders' "just desserts." The concept of case typification, as variously described by Sudnow and by Myers and Hagan, suggests that this systematic component is formed largely by comparisons of the offender, the offense, and the desirable outcome to more general notions of what each should look like (and has looked like) in similar and dissimilar sorts of cases. While formal legal criteria are important, one would not expect them to necessarily dominate the utility function, since at these stages mitigating circumstances are explicitly taken into account. And because the final outcome is uncertain, decision makers are assumed to be capable of assigning probabilities to the possible outcomes. At any given stage, whether initial screening, which charges to file, and what type of bargain to strike, decision makers will choose the line of action (dismissal or further processing) that yields the highest expected utility. Therefore, the random utility model for prosecutors' decision making explicitly states that decisions to further prosecute (and perhaps to plea bargain) are made on the basis of legal and "extralegal" criteria, plus a random component.

It is important to stress that this definition of utility maximization is not synonymous with a high conviction rate specifically, nor with bureaucratic efficiency generally, since prosecutors are also concerned with other issues concerning the crime, the offender, the victim, and the community. The Santa Barbara County District Attorney's Family Violence Prosecution Manual stresses that the victim as well as the case is to be protected, and that probation is a desirable alternative "indicating a second chance for the offender." Yet, it is nevertheless true that efficiency in screening cases is an organizational requirement that is typically defined by quick resolution of cases as well as a high conviction rate (Stanko, 1982; Myers and Hagan, 1979; Rosett and Cressey, 1976, p. 135).

\section{A Model for the Santa Barbara Diversion Program}

With the random utility model in hand, I can begin to specify what case factors could determine the utility of further processing by the Santa Barbara District Attorney's office, perhaps leading to diversion or outright dismissal. Unfortunately, I have no data on other, nondomestic cases processed during this period, and consequently I cannot compare the 
processing of various types of cases. Nor are there a sufficient number of cases handled before the start of the Family Violence Program with which to make pre- and postintervention comparisons. Two legitimate questions that cannot be addressed are did the processing of domestic violence cases change with the advent of the Family Violence Program, and are there differences between the processing of such cases and other personal violence cases?

The questions that can be asked are important nevertheless. First, was the diversion program used as intended? There were specific criteria defining the eligibility of offenders for the program, but conversations with individuals close to the process have suggested that the program may have been used for other purposes, such as an alternative sanction for serious cases with a low probability of conviction.

Second, how were cases of wife assault selected for possible prosecution or diversion? The amount of evidence and the number of witnesses should have a bearing on these decisions. It is also very likely that the DDA, in the course of her work, employed standardized accounts of what the "usual" case of spousal assault looks like, and who and what the victim and the offender in this case "usually" are. In other words, simply as an organizational requirement, the DDA would use typifications of one sort or another in order to readily deal with individual cases, through comparison to other sorts of cases. As a consequence, other factors, such as characteristics of the victim and the offender and their behavior, should also affect the decision-making process. Despite the mandate to pursue domestic cases more actively, the Deputy District Attorney was still accountable for her actions. "Weak" cases might still be dismissed later on in the process, perhaps after some expenditure of resources, and regardless of the outcome, decisions would have to be justifiable to superiors and, at some point, to a judge. If such schema were employed, one would expect to find that nonlegal characteristics affect decisions at each of the three decision points, and assuming that typifications were consistently used, I will attempt to specify identical models at all three stages, but will include new information in the models as it becomes available at later stages (e.g., new evidence).

\section{THE DATA AND SOME STATISTICAL ISSUES}

\section{The Sample}

The data set I will use consists of 199 domestic incidents forwarded to the Santa Barbara County District Attorney's office after the establishment of the special Deputy District Attorney's office and the start of the diversion program. Only cases recorded on incident or arrest reports are included. Furthermore, "domestic" incidents are defined as involving two adults in a past or present heterosexual romantic or conjugal relationship. And for the sake of conceptual clarity, only cases with a 
female victim and a male offender are included. The prosecution program was intended primarily for male offenders, as was the diversion alternative. Furthermore, the literature on domestic violence identifies this situation as somehow special in the eyes of the authorities. (For a full description of how the sample was collected and what it contains, see S. F. Berk and Loseke, 1980. Note that the sample used by Berk and Loseke contained 262 cases; I have dropped 63 cases that were forwarded before the diversion program became an option.)

The three decision points-to follow up a case, to file charges, and to divert-are represented by three dummy variables. Each dummy variable is coded 1 if the decision was positive (e.g., to divert a case). Furthermore, since the decisions are made sequentially and cases drop out of the system at each point, the sample size will be smaller at each step. For the initial decision to follow up a case, the sample consists of 199 cases. Of these 199 cases, the 96 cases that were followed up constitute the sample for the decision about arraignment. Finally, of these remaining 96 cases, the 75 cases that could be arraigned (as decided by the DDA) are the sample for the decision about possible diversion. The three discrete outcome measures and the sequential selection of cases pose several statistical and estimation problems that I will consider shortly.

One issue that I will not address concerns the charges that were actually filed or could have been filed had a case not been diverted. Unless an offender refused diversion, or violated the terms of the counseling program, what charges would have been filed are unknown. ${ }^{3}$ One cannot assume that diverted cases were solely misdemeanors, since some diverted cases that were later arraigned were arraigned on felony charges (which suggests that diversion was in some instances a bargaining tool). Furthermore, the charges filed may not represent the actual offense, but may instead represent overcharging as a first step in a plea bargaining process. However, if there was a larger sample at the diversion stage, I could, in principle, extend the analysis one additional step and consider the charges filed only when a case is arraigned.

To model these decisions, I have an array of exogenous variables, reflecting amount of evidence, the offender's prior record, other characteristics of the offense (such as severity), and characteristics of the victim, the offender, and their relationship. Means and standard deviations for these variables are presented in Table 1.

Since these are cases coded from official records, I stress that the information becomes more complete as the case proceeds farther along in the system. Incident reports, for example, contain whatever the police

\footnotetext{
${ }^{3}$ In principle, one could model the charges filed, and take account of the censoring caused by the diversion option. I chose not to, largely because I am interested in how offenders are selected for further processing, and not what charges are filed against them.
} 
decide to note about the incident. Similarly, arrest reports may contain omissions. For example, if, in an incident report, the police fail to note the number of witnesses, it is impossible to distinguish that situation from no witnesses unless the DDA decides to follow up on the case and, at the subsequent decision stage, more information is gathered. However, for my purposes, this apparent measurement error is no problem because I have the same information available to the DDA when she decides the fate of a case. What is potentially problematic, but for which there is no remedy, are variables that I fail to observe but which are known to the DDA. For example, cases that go on to the second decision stage, whether or not to file charges in court, may be taken up by the special investigator. Information that the investigator comes up with may not be recorded in the files, or only recorded in legally relevant terms (e.g., a case is dropped because the investigator discovers that the woman first attacked the man, but the official reason is lack of evidence).

In addition to case characteristics, I have one measure of organizational constraints placed on the DDA: the number of cases forwarded by the police in a given week. Presumably, when more cases are forwarded, the DDA may have to be more selective about following up "marginal" cases.

\section{Statistical Issues}

For each of the three discrete dependent variables, I will estimate a probit model (Pindyck and Rubinfeld, 1981, pp. 280-287; Amemiya, 1981; Maddala, 1983). ${ }^{4}$ Consequently, I am assuming that the probability of a case being followed up, of a case being arraigned, and of a case being diverted each follows a cumulative normal distribution function. Within the random utility framework, this is equivalent to saying that the probability that one choice has a higher utility is distributed according to the cumulative normal. ${ }^{s}$

A crucial statistical issue is the problem of sample selection bias. The systematic selection of cases at various stages in the criminal justice system will be reflected in any sample of cases examined at subsequent stages in the system. For example, cases that make it to the diversion decision are not necessarily representative of all cases that are forwarded to the District Attorney's office; rather, in all likelihood, they have been

\footnotetext{
${ }^{4}$ Maximum likelihood estimates were obtained using the LIMDEP program in MIT's TROLL package. As a check, the same models were estimated and identical results obtained using a nonlinear least squares program and the method of scoring (Jennrich and Moore, 1975).

5 The random utility model is not necessary in order to estimate either a probit or a logit model, since these are merely convenient functional forms. However, the random utility model does provide a behavioral foundation for the use of the cumulative normal that is more difficult to justify for the logit model (see Amemiya, 1981; Judge et al., 1980).
} 


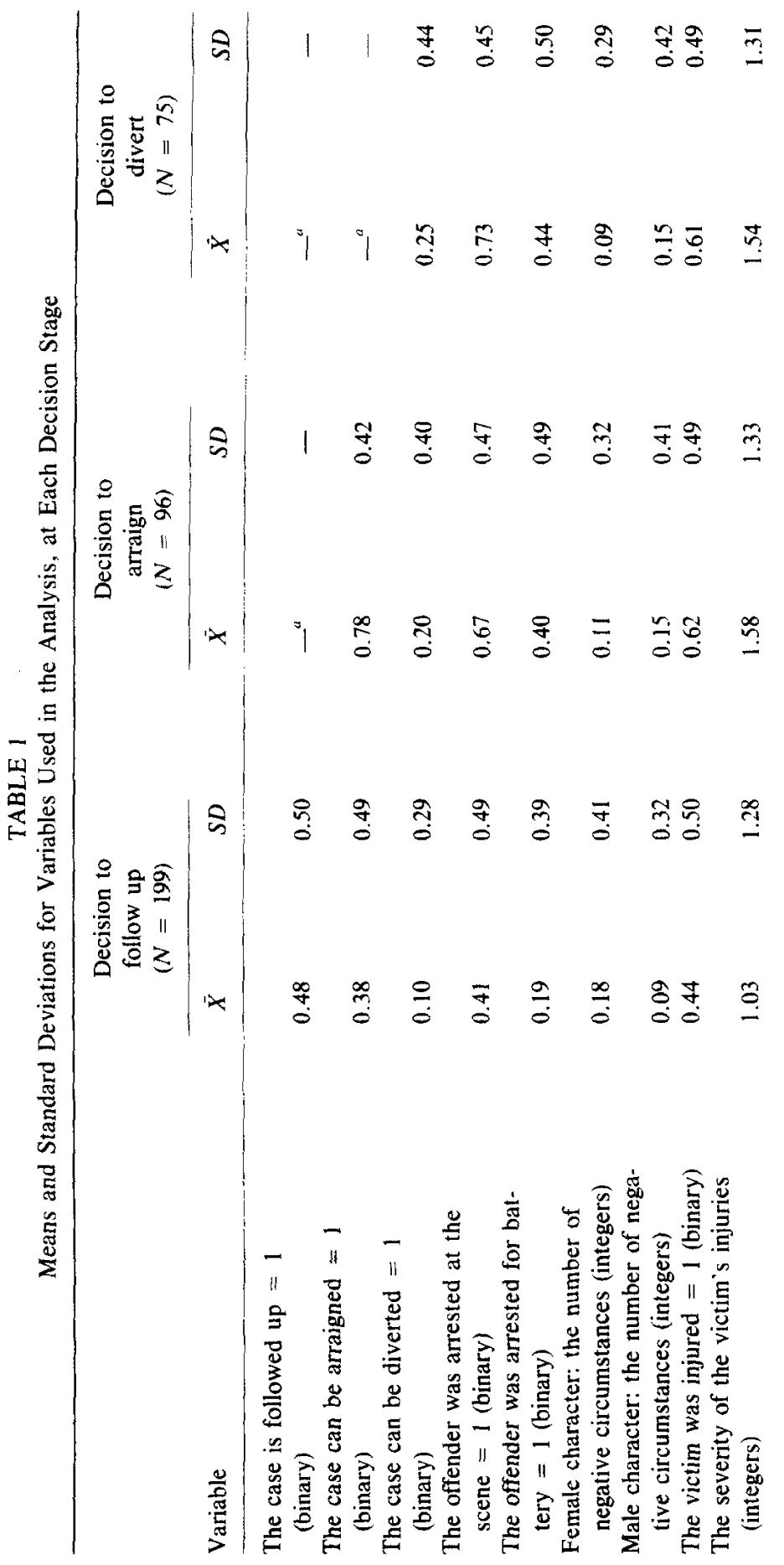




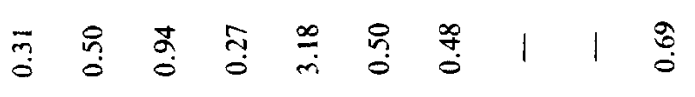

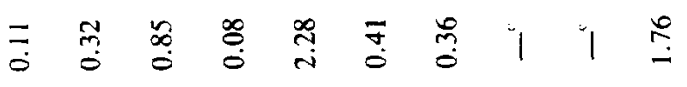

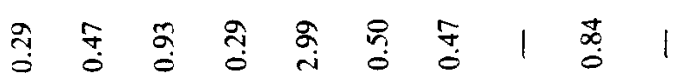

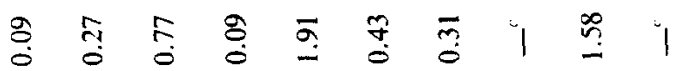

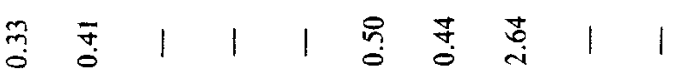

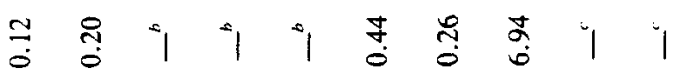

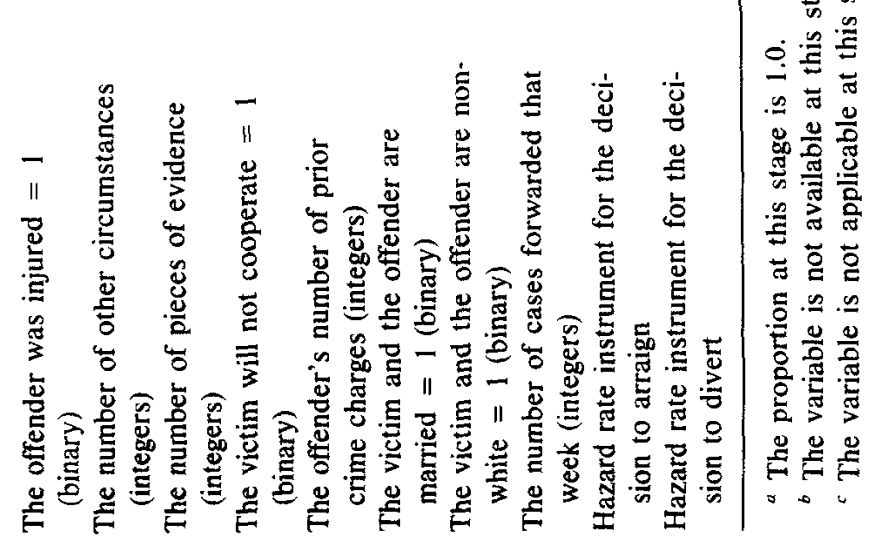


sampled according to certain criteria such as strength of evidence. Unless the decision process at a given step can be specified correctly (i.e., all the relevant variables can be included in the estimated model), parameter estimates will be biased because earlier selection processes remain confounded with the current decision process (Berk and Ray, 1982; Klepper, Nagin, and Tierney, 1983), and both internal and external validity are threatened. This funneling process corresponds to incidental sample selection (Goldberger, 1981; Berk and Ray, 1982), for which Heckman $(1976,1980)$ has derived an intuitively appealing and relatively convenient means of handling.

When a single selection process is at work for a given sample, Heckman's approach can be formulated as a two-equation model. The probability that a given observation in the full sample will be in the selected subsample is estimated with a probit model, that predicted probability is used to construct a hazard rate instrument for the likelihood of not being in the subsample, the hazard rate is included as a regressor in an equation for the continuous dependent variable of interest, and this substantive equation is estimated only for the selected subsample. Heckman's formulation can be thought of as an omitted variable problem, in which the hazard rate represents the likelihood of not being in the selected sample, and ignoring the hazard rate (i.e., the selection process) results in a specification error and all of its attendant consequences.

My approach will differ from Heckman's two-equation approach in several respects. First, Heckman's probit model for the selection process may be of no substantive interest, or of less substantive interest than the equation that follows it. In contrast, all three selection points here are substantively important, since each represents a distinct decision made by the DDA. Sccond, I will cstimate thrce equations in which, for the second and third equations, the predicted probabilities from the immediately prior step will be used to construct a hazard rate instrument for the current step. Put differently, the model for the decision about filing charges will include a hazard rate constructed from the model for the follow-up decision, and the model for the decision about diversion will include a similarly constructed instrument obtained from the model for the filing decision. Note that, as in Heckman's model, the sample size is reduced from one equation to the next, but unlike Heckman's model, I am extending the process to model a sequence of steps (see Klepper et al., 1983).

Finally, where Heckman's substantive equation has a continuous dependent variable and can be estimated with ordinary least squares, each decision is represented by a discrete dependent variable. The hazard rate formulation can be extended to the case of a discrete substantive process (e.g., Klepper et al., 1983), with the caveat that, while the probit estimates are maximum likelihood, the problem of heteroscedasticity 
remains, due to the nature of the hazard rate instrument (Heckman, 1976, 1980).

\section{DISCUSSION OF THE FINDINGS}

My data analysis strategy was twofold: to keep each model simple, and to build each equation sequentially rather than begin with a full specification. The rationale was that, because of the successively smaller samples from decision to decision, the nonlinear and therefore sensitive estimation procedures, and the sample selection correction, the equations were particularly susceptible to data problems such as lack of variance, multicollinearity, and outliers among the regressors. Simplicity seemed advisable under the circumstances. Furthermore, in order to better judge the sensitivity of the specifications to these types of problems, I began with simple models and worked up to believable specifications (see Kim, 1984 , for an alternative and more formal strategy). Since the useful graphical diagnostics for OLS regression models are difficult to interpret when estimating binary choice models, and alternative diagnostic procedures are just now being devised (e.g., Landwehr, Pregibon, and Shoemaker, 1984), this approach scemed a likely way to at least detect gross sorts of problems such as high multicollinearity. In the case of each model, the final product differed little from what I would have started with. I am explicit about the analytic strategy because it was a conscious choice, backed up by a theoretical model, and because researchers are often less than candid about their attempts to massage the data (Leamer, 1982). Finally, whenever possible, because of a prior expectations, I will use the .05 level and one-tailed significance tests for the probit coefficients.

\section{The Decision to Follow Up an Incident}

The results for the analysis of the first decision, whether or not to follow up an incident, are reported in Table 2. The regressors reported in Table 2 can be divided into three basic categories: characteristics of the principals, features of the incident, and characteristics of the District Attorney's office.

First of all, if the offender was arrested at the scene, the probability of there being further investigation is increased by about .5 and the effect is significant at the .05 level for a one-tailed test (I expected a positive effect). Multiplying the probit coefficients by .4 gives them a probability interpretation at the .50 point in the cumulative normal distribution function (Amemiya, 1981). In other words, holding all else constant, if the incident has a 50-50 chance of being followed up, an arrest at the scene will make it a certainty that the case goes to the next stage in the decision process. (I will continue to interpret the coefficients at the .5 point in the cumulative normal. This is the steepest point in the curve, and therefore the changes in the probabilities will be the greatest.) 
TABLE 2

A Probit Model for Whether or not an Incident Is Followed up $(N=199)$

\begin{tabular}{lcc}
\hline Variable & Coefficient & Asymptotic $t$ value \\
\hline $\begin{array}{l}\text { Intercept } \\
\text { The offender was arrested at the } \\
\text { scene }=1 \text { (binary) }\end{array}$ & -0.391 & -0.96 \\
$\begin{array}{l}\text { Female character: the number of } \\
\text { negative circumstances (integers) }\end{array}$ & 1.326 & -0.912 \\
$\begin{array}{l}\text { Male character: the number of nega- } \\
\text { tive circumstances (integers) }\end{array}$ & 1.322 & 2.59 \\
$\begin{array}{l}\text { The severity of the victim's injuries } \\
\text { (integers) }\end{array}$ & 0.646 & 5.65 \\
$\begin{array}{l}\text { The offender was injured }=1 \\
\text { (binary) }\end{array}$ & -1.449 & -3.16 \\
$\begin{array}{l}\text { The number of other circumstances } \\
\text { (integers) }\end{array}$ & 0.325 & 1.14 \\
$\begin{array}{l}\text { The victim and the offender are mar- } \\
\text { ried }=1 \text { (binary) }\end{array}$ & -0.434 & -1.71 \\
$\begin{array}{l}\text { The victim and the offender are non- } \\
\text { white }=1 \text { (binary) }\end{array}$ & 0.429 & 1.61 \\
$\begin{array}{l}\text { The number of domestic incidents } \\
\text { forwarded that week (integers) } \\
R^{2}=.50^{\circ}\end{array}$ & -0.086 & -1.86 \\
\hline
\end{tabular}

${ }^{a}$ Calculated with this formula (Maddala, 1983, p. 38): $R^{2}=\mathrm{V}(p) / \mathrm{V}(\mathrm{V})$, where $p$ is the predicted probability from the probit equation, and $Y$ is the dummy dependent variable.

Two overlapping interpretations are possible for the effect of an onthe-scene arrest. First, because an arrest report (as opposed to a field card or an incident report) is forwarded to the Deputy District Attorney, the incident is likely to be better documented, thus giving the DDA more information with which to make a decision. Second, as S. F. Berk and Loseke (1980) found when attempting to explain police arrest decisions (using this same data set and arrest variable; see Worden and Pollitz, 1984, for similar results utilizing a different data set), such decisions depend as much on situational factors as on occupational or individual predispositions. In exercising their most severe option, arrest, the police respond to the nature of the event, which itself is likely to be severe. These incident characteristics will no doubt be documented in the arrest report as a justification for the arrest. Altogether, the adequate documentation of a severe incident makes it much more likely that the Deputy District Attorney will follow it up. In terms of the random utility model, more severe and better documented incidents increase the expected utility of further investigation.

Indicators of male and female character also play a central role in the DDA's decision making. Here, I have constructed character indices, 
made up of negative circumstances of a given incident (police seidom documented positive circumstances). For females, the character index is coded 0 if there were no negative circumstances, is coded 1 if either the victim was alleged by the offender to have also been violent or she was noted by the police to have been drinking, and is coded 2 if the victim was alleged to have been violent and noted to have been drinking. In the case of males, the character index has a range of 0 to 3, reflecting the number of circumstances noted by the police from among the following: was there a temporary restraining order in effect against the offender, was a weapon present, and was the offender either verbally or physically abusive to the police? Note that both indices give equal weight to their respective components. Individually, these are relatively infrequent occurrences and I could not represent them with separate dummy variables (lack of variance created estimation problems-see Table 1 for the index means); nor do I have any theory to dictate the appropriate weighting scheme.

The coefficient for the index of female character shows that for every additional negative event, the probability of following up an incident is dccreased by about .37 . The coefficient for males indicates that every additional negative circumstance increases the probability of the case being followed up by about .5. In each case, the maximum value for the index is 2 , which represents a decrease of .74 for victims and an increase of 1.0 for offenders. Both coefficients are significant at the .05 level for a one-tailed test, and both effects are consistent with past research and with my a priori expectations. Stanko's (1982) description of a "standup witness" is particularly apt here, as is Littrell's (1979, pp. 137-141) description of the defendant's worthiness for prosecution. Events that either raise doubts about the victim as a "victim," or confirm that the offender is guilty of something and deserves attention, affect the DDA's decision about further processing.

Injuries to either party also affect the DDA's decision about the incident. Injuries to the victim were represented by a severity of injury index (which has been described and modeled elsewhere-sce Berk et al., 1983 for details), as a means of gauging the apparent seriousness of the assault. The index ranges from 0 (no noted injuries) to 6 (serious injuries, including broken bones or teeth and internal injuries), although the highest value for the sample is 5 (internal injuries). Every one point increase in the severity of injuries to the victim increases the probability of follow up by about .26 , an effect that is statistically significant for a one-tailed test.

In contrast, injuries to the offender significantly decrease the probability of a case beng followed up by about .58, all other things held constant. This variable is coded as a simple dummy variable, unlike the severity index of victims, and reflects comments in the police data that the offender was either injured or would seek medical attention (the two situations 
do not always coincide; some offenders were noted as seeking medical attention, but no mention was made of injuries). The negative effect represents a decrease in the expected utility of a case to the DDA, perhaps because it is harder to portray the woman and man as victim and offender, respectively, when the man has been injured. Injuries to both parties might indicate particularly severe incidents, in which the victim inflicted injuries in self-defense, but mutual injuries were noted very infrequently. At the same time however, there is informal evidence that some offenders' injuries were self-inflicted, perhaps in the course of the violence, or, more likely, because the offender had been drinking and/or was physically out of control, and therefore likely to injure himself. Recall that the information on the incident and arrest reports is all that the DDA has to work with at this point; self-inflicted injuries could only be recognized if the police made note of them, or if the case is followed up and an investigator later makes that discovery.

The other measured characteristic of the incident is the number of other circumstances mentioned by the police that did not in some manner address the issue of individual character: whether or not there was property damage and whether or not the police witnessed the violence. Lack of variance for the individual components also forced the creation of an index which, again, gives equal weight to these circumstances. The coefficient for the index is not significant at the .05 level for a one-tailed test, perhaps because the major factors are already captured in the character indices. Lack of variance remains a possible explanation as well.

The results for other victim and offender traits are mixed. The coefficient for a victim and offender who are married (as opposed to divorced, separated, or cohabiting) is negative and significant at the .05 level for a one-tailed test. I was uncertain about the magnitude of the effect because, on the one hand, it may be more difficult to get women to cooperate if they are married to the offender (implying a negative coefficient). On the other hand, since the Deputy District Attorney's function was to prosecute cases of domestic violence, the legal relationship between victim and offender should presumably have no bearing on the decision to follow up a case (implying a zero coefficient). The effect seems to be an indicator of the DDA's assessment of potential (or typical) problems such as victim noncooperation, or possibly of what a desirable outcome is for married couples.

The positive effect for nonwhite couples is troubling, although it is not significant at the .05 level for a one-tailed test, because I expected a negative coefficient. Originally, I specified the victim's race, thinking that nonwhite victims might be viewed as less credible witnesses (Stanko, 1982). This implied a negative effect, but the estimated effect was positive. As a test, I replaced the victim's race with the offender's race, and the coefficient was still negative and, in absolute value, slightly larger. As 
a compromise, I constructed the variable for nonwhite couples, since most couples are of the same race, but I am perplexed as to the reason for a positive effect. I have left the couple's race in the equation only because the coefficient is virtually identical for the three representations, but I do not attribute the positive sign to discrimination, nor can I find anything extraordinary about these cases that race serves as a proxy for.

One strong possibility is that the DDA indeed had extra information at this stage, which did not appear in the files. For example, there are couples with repeat incidents in the data set, but attempts to take account of these multiple incidents (each of which appears as a separate case) proved fruitless. ${ }^{6}$ Ultimately, the sign of the coefficient may simply be due to Type I error.

The final variable in the model reflects the workload within the DDA's office. Each additional case forwarded in a given week reduces the probability of a given case being followed up by about .03 . The effect is significant at the .05 level for a one-tailed test, and the impact of additional cases is rather small. However, with an average caseload of approximately seven cases (see Table 1), one additional case over the average would experience a reduction in probability of about .24 . One case more would experience a reduction of about .28, and so on. Evaluations of the Santa Barbara Family Violence Program demunstrated that increasing the number of cases forwarded, as well as the quality of their documentation, had virtually no impact on the number of offenders sanctioned by the District Attorney's office (Berk et al., 1980; Berk et al., 1982): there seemed to already be a sufficient number of adequately documented cases to keep the special DDA busy. That interpretation is consistent with the findings here, and it seems inconsistent with Heumann's (1977) argument that caseload pressures have been grossly overstated.

With the exception of the racial effect, these results for the follow-up decision are as expected. The DDA will follow up better documented and more serious cases because these cases maximize her utility. There is a clear indication in the coefficients for male and female character, married couples, and for injured offenders, that the DDA has some notions of what domestic cases should or should not be, or which domestic cases can or cannot be followed up, holding constant relevant legal criteria. As we shall see, these notions, or typifications, become especially important later, when possible sanctions are considered (i.e., diversion).

One variable that $\mathbf{l}$ also considered, and thought would play a role, is the age of the victim. Older victims might be thought of as less credible,

\footnotetext{
${ }^{6}$ I used dummy variables for the repeat incidents, in each of the three equations, but the variables were not significant. These dummy variables, had they worked, would have also controlled for possible correlations among the residuals for the repeat couples.
} 
especially if their age was an indication of the length of the relationship. For whatever reasons, because the variable is not important, or because it does not measure very well the length of the relationship, age had absolutely no impact on the follow-up decision. Largely because of measurement problems (due to missing data problems), I dropped it from the analysis.

Recalling Myers and Hagan's (1979) argument that strong cases are described in legally relevant terms, I also examined a variety of interactions between the indices for victim, offender, and situation characteristics and a variety of other variables. The rationale was that if descriptions of strong cases (based on legal criteria) differed from descriptions of weaker cases, as Myers and Hagan indicate, cases with good and/or bad characteristics along various dimensions might also be handled in different ways. For example, if the victim was severely injured, other, more positive case features may be viewed more negatively as a result. I tried a variety of configurations, in an admittedly exploratory fashion, but there was no consistent pattern in terms of statistical significance, nor even in terms of coefficients' signs. Collinearity with other variables and lack of variance in the interaction terms are the most likely explanations for this inability to explain very much, and therefore I do not report any of these results.

\section{The Decision to File Charges}

In contrast to the results for the follow-up decision, the findings for the arraignment decision, reported in Table 3, are virtually nonexistent. The two most striking results are puzzling at best: the severity of the victim's injuries reduces the probability of charges being filed; injuries to the offender increase the probability of charges being filed. Of the remaining substantive coefficients, only that for the offender's prior record is significant, and unlike the coefficients for injuries, it is in the predicted direction (positive). I again tried a variety of interaction terms, similar to those tested in the first equation, but the results were altogether disappointing. As before, there was no consistent pattern, and there were certainly no effects that dramatically improved the overall story. Here too, I will not report these efforts.

Rather than spend time attempting to interpret the findings individually, I feel that a simple account is available for the model as a whole. If one looks at the number of cases that are forwarded to the next step (i.e., charges could be filed and therefore a decision about diversion must be made), fully $78 \%$ of the cases that are followed up either result in diversion or arraignment. In other words, the decision to initially allocate resources (follow up a case) is, for the vast majority of cases, effectively a decision to prosecute. It may be that largely idiosyncratic factors cause cases to 
TABLE 3

A Probit Model for Whether or not Charges May Be Filed $(N=96)$

\begin{tabular}{|c|c|c|}
\hline Variable & Coefficient & Asymptotic $t$ value \\
\hline Intercept & -0.180 & -0.43 \\
\hline $\begin{array}{l}\text { The offender was arrested for bat- } \\
\text { tery }=1 \text { (binary) }\end{array}$ & 0.469 & 1.17 \\
\hline $\begin{array}{l}\text { Female character: the number of } \\
\text { negative circumstances (integers) }\end{array}$ & 0.340 & .057 \\
\hline $\begin{array}{l}\text { Male character: the number of nega- } \\
\text { tive circumstances (integers) }\end{array}$ & -0.460 & -0.71 \\
\hline $\begin{array}{l}\text { The severity of the victim's injuries } \\
\text { (integers) }\end{array}$ & -0.452 & -2.20 \\
\hline $\begin{array}{l}\text { The offender was injured }=1 \\
\text { (binary) }\end{array}$ & 1.642 & 1.83 \\
\hline $\begin{array}{l}\text { The number of pieces of evidence } \\
\text { (integers) }\end{array}$ & 0.109 & 0.49 \\
\hline $\begin{array}{l}\text { The victim will not cooperate }=1 \\
\text { (binary) }\end{array}$ & 0.029 & 0.05 \\
\hline $\begin{array}{l}\text { The offender's number of prior } \\
\text { crime charges (integers) }\end{array}$ & 0.137 & 1.66 \\
\hline $\begin{array}{l}\text { The victim and the offender are } \\
\text { married }=1 \text { (binary) }\end{array}$ & -0.110 & -0.29 \\
\hline $\begin{array}{l}\text { The victim and the offender are } \\
\text { nonwhite }=1 \text { (binary) }\end{array}$ & 0.577 & 1.36 \\
\hline $\begin{array}{l}\text { Hazard rate instrument } \\
\qquad R^{2}=.22^{b}\end{array}$ & 0.729 & 2.05 \\
\hline
\end{tabular}

Calculated with the predicted probabilities from the equation for whether or not a case is followed up.

${ }^{b}$ See Table 2 for the formula used to calculate $R^{2}$.

fall apart after the first decision to follow them up. Put a bit differently, as more information becomes available for a particular case, the DDA's initial assessment of the case and the likelihood of successful prosecution may change. For example, self-inflicted injuries to the offender may become known after a criminal investigator is sent out to collect evidence and discover other details of the incident. A second explanation, which does not preclude the first, is that the DDA may be looking ahead to the next step and keeping borderline cases alive in order to utilize the diversion option. If so, the first decision becomes all the more crucial, since that is where the DDA is choosing to maximize her utility with respect to prosecution. And having made the initial decision to follow up, the DDA is perhaps reluctant to drop the case altogether. As Myers and Hagan (1979) have pointed out, the initial decision to follow up is 
a decision to allocate resources; if a diversion option is available, resources do not necessarily have to be lost when a case begins to unravel. ${ }^{7}$

\section{The Decision to Divert}

The findings for the third model, whether or not an offender is diverted from prosecution, are reported in Table 4. One can now begin to see emerging an overall logic to the DDA's decision making across the three decision stages. Diversion is apparently an alternative sanction for cases that might be weak, or for which counseling would be the outcome anyway, regardless of the offender's suitability for diversion. My suspicions were that the diversion criteria were being applied, but that for certain offenders these criteria were being loosened. As becomes clear with this model, the DDA may have had appropriate courses of action in mind from the very start.

Recall that the criteria for diversion include the following, for which I have measures: the offender has not been convicted of a domestic violence offense, the victim's injuries are not serious, and the offender has no significant criminal record. ${ }^{8}$ In addition, three criteria for which I do not have measures are an offender's judged responsibility, an offender's desire for diversion, and a victim's objections, if any, to diversion. In principle, only these factors should affect the decision to divert; presumably other matters such as the weight of evidence and organizational demands have already been considered before or at the decision that charges can be filed.

The results in Table 4 indicate that factors other than the three measured criteria have a role in the decision-making process. The severity of the victim's injuries appears to have little bearing on the decision to divert. The coefficient is negative as expected, but it is not statistically significant. However, prior record does make a difference, with each additional prior crime charge significantly reducing the probability of diversion by about .17. Since, for most offenders, the range of the variable is 0 to 2 (but several offenders have more), the maximum effect is a reduction in the probability of .34 . This is a moderate effect, but when viewed alongside

${ }^{7}$ I also specified a two-equation model, dropping the second equation and estimating the diversion equation with the larger sample. My reasoning was that if the follow-up decision was a decision to prosecute, and only idiosyncratic factors forced cases out later, the larger sample was effectively the pool from which diversion cases were selected. The results were nearly identical to those for the reported third equation, except that the $t$ statistics were uniformly lower. The larger sample merely adds more observations with zero values for the dependent variable, and no extra explanatory power was to be had.

${ }^{8}$ Significant criminal record is not defined specifically in the Family Violence Prosecutor's Manual. The DDA therefore has the discretion of deciding what significant means. If there was more variance in criminal records (most offenders had none or one prior charge), I could explore how prior record is used to relate particular cases to the DDA's ideas of what domestic cases typically involve (see Sudnow, 1964). 
TABLE 4

A Probit Model for Whether or not a Case Is Diverted $(N=75)$

\begin{tabular}{lcc}
\hline Variable & Coefficient & Asymptotic $t$ value \\
\hline $\begin{array}{l}\text { Intercept } \\
\text { The offender was arrested for bat- } \\
\text { tery }=1 \text { (binary) }\end{array}$ & -0.960 & -0.78 \\
$\begin{array}{l}\text { Female character: the number of } \\
\text { negative circumstances (integers) }\end{array}$ & 1.368 & 1.56 \\
$\begin{array}{l}\text { Male character: the number of nega- } \\
\text { tive circumstances (integers) }\end{array}$ & 2.083 & 1.92 \\
$\begin{array}{l}\text { The severity of the victim's injuries } \\
\text { (binary) }\end{array}$ & -1.439 & -1.62 \\
$\begin{array}{l}\text { The offender was injured }=1 \\
\quad \text { (binary) }\end{array}$ & -0.332 & -1.25 \\
$\begin{array}{l}\text { The number of pieces of evidence } \\
\text { (integers) }\end{array}$ & 1.024 & 0.85 \\
$\begin{array}{l}\text { The victim will not cooperate }=1 \\
\text { (binary) }\end{array}$ & -0.296 & -0.78 \\
$\begin{array}{l}\text { The offender's number of prior } \\
\text { criminal charges (integers) }\end{array}$ & 2.051 & 2.22 \\
$\begin{array}{l}\text { The victim and the offender are } \\
\text { married = 1 (binary) }\end{array}$ & -0.421 & -2.05 \\
$\begin{array}{l}\text { The victim and the offender are } \\
\text { nonwhite = 1 (binary) }\end{array}$ & 1.154 & 1.99 \\
$\begin{array}{l}\text { Hazard rate instrument } \\
\quad R^{2}=.48^{b}\end{array}$ & -0.402 & -0.43 \\
\hline
\end{tabular}

"Calculated with the predicted probabilities from the equation for whether or not charges may be filed.

${ }^{b}$ See Table 2 for the formula used to calculate $R^{2}$.

the null effect for the victim's injuries, is not what one would expect if the diversion requirements were being strictly applied. According to the program requirements, a record should strongly reduce the chances of ending up in diversion, just as severe injuries should. However, since very few of the offenders who reached this stage had prior charges for domestic incidents, I have included all charges in a single variable. Consequently, the prior crime charges may represent a "watered down" effect.

The coefficient for the other measure of the severity of the incident, an arrest on battery charges (a misdemeanor), is not statistically significant since I expected a negative effect. I used this variable here (and in the second equation) rather than the arrest variable from the first equation because of the large proportion of offenders who were arrested. Arrest was such a strong predictor and so highly collinear with other variables after the follow-up decision, that it impaired the models for the second and third stages. However, since almost half of all arrests were on battery 
charges, the alternative specification represents the most common arrest situation. Furthermore, battery is a personal violence charge, albeit a misdemeanor charge, and that fact should lessen the probability of ending up in counseling. And since the vast majority of arrests in the sample were on misdemeanor charges, it is hard to argue that battery is less severe when compared to other cases. In retrospect, it is easy to see why a positive effect is consistent with my overall expectations about prosccutor decision making. Offenders arrested on battery charges are, in effect, being sanctioned at this stage: conviction for battery typically involves probation and counseling anyway (for first-time offenders certainly). As a consequence, I am inclined to take the coefficient's sign seriously rather than attributing it solely to Type I error.

One of the important elements affecting a prosecutor's decisions is the desirable outcome (e.g., Sudnow, 1964). Whereas in earlier stages, going on to the next step meant for the victim increasingly closer scrutiny, and for the offender an increased likelihood of sanctions, diversion represents an easier option for the victim and a more lenient "punishment" for the offender. As expected, each additional negative aspect of the victim's character-drinking and alleged violence-now significantly increases the probability of diversion by about .83 , while each additional negative aspect of the offender's character now significantly decreases the likelihood of counseling by about .58. The model for the follow-up decision showed that offenders married to their victims were less likely to continue in the system. Here, I find that married couples are more likely to be diverted, and the effect is significant at the .05 level for a one-tailed test. Married women are possibly viewed as having more to lose if the offender is prosecuted; in terms of the victim, prosecution may be the least desirable outcome. Given that they have entered the system, offenders married to their victims are more likely to end up in counseling, perhaps because the DDA is reluctant to prosecute the husband, or perhaps because counseling is seen as having a better chance of "helping" couples with an established relationship. In addition, if the victim has stated that she will not cooperate with prosecution efforts, there is a large and statistically significant increase in the probability of diversion of about .82 . If the case will be difficult to prosecute because of the victim's noncooperation, diversion is a way of keeping the offender under control with the threat of prosecution.

As expected, there is no effect for evidence, nor are there effects for nonwhite couples, nor for injuries to the offender. The variable representing evidence in the second and third equations is an index constructed as the sum of the index from the first equation and the number of the following characteristics: hospital reports documenting the victim's injuries, photos of the victim's injuries, other physical evidence, and witnesses to the incident other than the police. 
In terms of the DDA's utility function, good cases maximize utility, and I strongly suspect (based on field observations) $)^{9}$ that, at the time of the decision to file charges, there may have been anticipation of the diversion option. This is certainly a conclusion that one could draw from the combined results of the second and third equations. The formal criteria for diversion have little impact on the diversion decision, but other criteria, more relevant to the construction of a good case and the likely outcome generally do play a role: the charges the offender was arrested on, the character of both the victim and the offender, and the victim's unwillingness to cooperate. Cases that were originally considered borderline may have been carried along with the intent of diverting them later. In the latter two equations, Heckman's hazard rate instruments are essentially proxies for measures of the DDA's intent, and in this context, one can give an interpretation to the positive and statistically significant (for a two-tailed test) hazard rate instrument in the second equation. Since the hazard rate measures the likelihood of not remaining in the selected sample, the positive effect indicates that "high risk" cases at the first decision are more likely to be moved along at the arraignment decision as well. The hazard rate instrument in the third equation is not statistically significant, but this probably reflects the inability to explain very much in the second equation, one result of which is a weak instrument. In addition, dropping the hazard rate instruments from the latter two equations has little substantive impact on either model. The second equation is weak to begin with, and therefore dropping the instrument can do little to affect it. The instrument constructed from the second equation is itself weak, and its role as an explanatory variable in the third equation is minor at best.

It is also important to remember that the sample size of 75 at the final stage makes the estimated equation particularly vulnerable to data problems of all sorts. My attempts to include interaction terms in the third equation were as fruitless as those for earlier equations, and the small sample size apparently exacerbated lack of variance problems. However, on the positive side, model estimates at all three steps were remarkably stable for a variety of specifications (recall the model building strategy). While there are anomolies, there is a fairly consistent pattern in the data, leading to a reasonable substantive account of the DDA's decision-making strategy.

\section{CONCLUSIONS}

The analysis of the decision-making process within the special DDA's office in Santa Barbara largely confirms my expectations, with some important additions. The criteria used to make early screening decisions involve more than what would be admissible in a courtroom. In particular,

\footnotetext{
${ }^{9}$ Donileen R. Loseke conducted the field research component of this study.
} 
decisions made before a case might go to trial afford an opportunity for a variety of mitigating circumstances to be taken into account. To characterize this process in terms of the random utility model, the DDA screens out bad cases early, and makes use of the criminal investigator to gather more information about the other, especially borderline cases. Good cases have good victims and bad offenders, sufficient evidence, and are serious enough to warrant attention from authorities. Given her knowledge and experience about what good and bad cases are, and the legal and organizational constraints placed upon her, the DDA chose to maximize her utility (which includes efficient use of the criminal investigator) at the first step. Any dropping of cases at later points is apparently due to unique features of the individual cases. With an available diversion option, the DDA can keep certain cases alive that would otherwise be dropped; they can now be diverted. There is nothing in the criteria for diversion that contradicts the legal or "extralegal" criteria for a good case. In fact, they both compliment and extend the definition of a good case. Thus, diversion into counseling is yet another available sanction, less severe than either probation or prosecution, which allows the DDA to retain control through the threat of future prosecution.

Does this mean that the diversion program was not used as intended? The answer is that its use was apparently expanded beyond the formally stated intent. I have no evidence that qualified offenders were denied counseling, but other, perhaps formally unqualified offenders may have been diverted. If the DDA's mandate to prosecute family violence cases is broadly construed, as my analyses suggest that it was, then retaining control over offenders whose cases might otherwise be dismissed is consistent with that mandate. And diverting weak cases is certainly consistent with other organizational goals such as quick and successful processing of cases. At the same time, field observations indicate that counseling resources were taxed by this extraordinary use of the program, perhaps undermining the intent of providing counseling to a certain class of domestic violence offenders.

The question remains, however, does this use of "extralegal" criteria constitute discriminatory behavior on the part of the DDA? As Nagel (1983) has argued, one must look at the relative weight of legal and extralegal factors in a given situation, as well as the outcome. Looking solely at the outcome, I would not argue that the Santa Barbara DDA acted in a discriminatory or unjust manner by paying attention to otherthan-legally defined criteria in her decision making. Given organizational pressures for the "good case," as well as a finite set of resources, the DDA was able to prosecute a certain number of wife batterers and bring a few more under the control of authorities through the counseling option. And since the impact of extra-legal factors varied by decision, it is virtually impossible to maintain that if discrimination against certain 
groups was a feature of the DDA's decision making, it was practiced in any consistent manner. The usual picture brought to mind by claims of discrimination is one of single-minded intent that will not be context specific (see the remarks by Martin and Roy in the opening paragraph of this article). This is not what the findings of my analyses show.

And more generally, in situations where gender, racial, or other types of discrimination are at issue, one cannot simply assume that extra-legal considerations are inappropriate, or that they are not in some way proscribed by case law (Nagel, 1983). As I have done here, the specific context of decision making has to be examined, as do the outcomes. Future research should concentrate on the interplay between organizational demands and the details of individual cases, and how that interplay leads ultimately to particular decisions (see Messinger, Berecochea, Rauma, and Berk, in press, for an example). Only then, by considering what and how various outcomes were achieved, can decisions made by judges, prosecutors, and other criminal justice officials be better understood.

\section{REFERENCES}

Amemiya, T. (1981), "Qualitative response models: a survey," Journal of Economic Literature $19,1483$.

Berk, R. A., Berk, S. F., and Loseke, D. R. (1979), "A preliminary evaluation of the santa barbara family violence program, " unpublished manuscript, University of California, Santa Barbara.

Berk, R. A., Berk, S. F., Loseke, D. R., and Rauma, D. (1983), "Mutual combat and other family violence myths," in The Dark Side of Families: Current Family Violence Research (David Finkelhor, Richard J. Gelles, Gerald T. Hotaling, and Murray A. Straus, Eds.), Sage, Beverly Hills, Calif.

Berk, S. F., and Loseke, D. R. (1980), " 'Handling' family violence: situational determinants of police arrest in domestic disturbances," Law and Society Review 15, 317.

Berk, R. A., Loseke, D. R., Berk, S. F., and Rauma, D. (1980), "Bringing the cops back in: a study of efforts to make the criminal justice system more responsive to incidents of family violence," Social Science Research 9, 193.

Berk, R. A., Rauma, D., Loseke, D. R., and Berk, S. F. (1982), “Throwing the cops back out: the decline of a local program to make the criminal justice system more responsive to incidents of domestic violence," Social Science Research 11, 245.

Berk, R. A., and Ray, S. (1982), "Selection biases in sociological data," Social Science Research 11, 352.

Bittner, E. (1967), "The police on skid-row: a study of peace keeping," American Sociological Review 32, 699.

Bittner, E. (1980), The Functions of the Police in Modern Society, Oelgeschlager, Gunn \& Hain, Cambridge, Mass.

Brereton, D., and Caspar, J. D. (1982), "Does it pay to plead guilty? Differential sentencing and the functioning of criminal courts," Law and Society Review 16, 45.

Cole, G. F. (1970), "The decision to prosecute," Law and Society Review 3, 331.

Dobash, R. E., and Dobash, R. (1979), Violence Against Wives: A Case Against Patriarchy, Free Press, New York.

Goldberger, A. S. (1981), "Linear regression after selection," Journal of Econometrics $15,357$. 
Grant, J. D., Grant, J., and Toch, H. H. (1982), "Police-citizen conflict and decisions to arrest," in The Criminal Justice System: A Social-Psychological Approach, (V. J. Konecni and E. B. Ebbeson, Eds.), Freeman, San Francisco.

Hagan, J., Hewitt, J. D., and Alwin, D. F. (1979), "Ceremonial Justice: crime and punishment is a loosely coupled system," Social Forces 58, 506.

Hagan, J., Nagel, I. H., and Albonetti, C. (1980), "The differential sentencing of whitecollar offenders in ten federal district courts," American Sociological Review 45, 802.

Hall, D. J. (1975), "The role of the victim in the prosecution and disposition of a criminal case," Vanderbilt Law Review 28, 931.

Hanushek, E. A., and Jackson. J. E. (1977), Statistical Methods for Social Scientists, Academic Press, New York.

Harvey, A. C. (1981), The Econometric Analysis of Time Series, Halsted, New York.

Heckman, J. J. (1976), "Sample selection bias as a specification error," Econometrica 45, 153.

Heckman, J. J. (1980), "Sample selection bias as a specification error with an application to the estimation of labor supply functions," in Female Labor Supply: Theory and Estimation, (J. P. Smith, Ed.), Princeton Univ. Press, Princeton, NJ.

Heumann, M. (1977), Plea Bargaining, Univ. of Chicago Press, Ill.

Hey, J. D. (1979), Uncertainty in Microeconomics, New York Univ. Press, New York.

Jennrich, R. I., and Moore, R. H. (1975), "Maximum likelihood estimation by means of nonlinear least squares," American Statistical Association, 1975 Proceedings of the Statistical Computing Section 57.

Johnson, W. T., Petersen, R. E., and Wells, L. E. (1977), "Arrest probabilities for marijuana users as indicators of selective law enforcement," American Journal of Sociology 83, 681 .

Judge, G. G., Griffiths, W. E., Hill, R. C., and Lee, T.-C. (1980), The Theory and Practice of Econometrics, Wiley, New York.

Kim, J.-O. (1984), "An approach to sensitivity analysis in sociological research," American Sociological Review 49, 272.

Kleck, G. (1981), "Racial discrimination in criminal sentencing: a critical evaluation of the evidence with additional evidence on the death penalty," American Sociological Review 46, 783.

Klepper, S., Nagin, D., and Tierney, L. (1983), "Discrimination in the criminal justice system: a critical appraisal of the literature and suggestions for future research," in Research on Sentencing: The Search for Reform, (A.Blumstein, J. Cohen, S. E. Martin, and M. H. Tonry, Eds.), Vol. 2, National Academy Press, Washington, DC.

Landwehr, J. M., Pregibon, D., and Shoemaker, A. C. (1984), "Graphical methods for assessing logistic regression models," Journal of the American Statistical Association 79,61 .

Leamer, E. E. (1982), "Let's take the con out of econometrics," American Economic Review 73, 31.

Littrell, W. B. (1979), Bureaucratic Justice: Police, Prosecutors, and Plea Bargaining, Sage, Beverly Hills, Calif.

Luce, R. D., and Raiffa, H. (1957), Games and Decisions: Introduction and Critical Survey, Wiley, New York.

Maddala, G. S. (1983), Limited-Dependent and Qualitative Variables in Econometrics, Cambridge Univ. Press, Cambridge.

Martin, D. (1976), Battered Wives, Pocket Books, New York.

Mather, L. M. (1974), "Some determinants of the method of case disposition: decisionmaking by public defenders in Los Angeles," Law and Society Review 8, 187.

Maynard, D. W. (1982), "Defendant attributes in plea bargaining: notes on the modeling of sentencing decisions," Social Problems 29, 347. 
Messinger, S. L., Berecochea, J. E., Rauma, D., and Berk, R. A. (in press), "The foundations of parole in California," Law and Society Review.

Myers, M. A., and Hagan, J. (1979), "Private and public trouble: prosecutors and the allocation of court resources," Social Problems 26, 439.

Nagel, I. H. (1983), "The legal/extra-legal controversy: judicial decisions in pretrial release," Law and Society Review 17, 482.

National Advisory Commission on Criminal Justice Standards and Goals (1973), Courts, United States Govt. Printing Office, Washington, DC.

Newman, D. J. (1956), "Pleading guilty for considerations: a study of bargain justice," Journal of Criminal Law, Criminology, and Police Science 46, 780.

Peterson, R. D., and Hagan, J. (1984), "Changing conceptions of race: towards an account of anomolous findings of sentencing research." American Sociological Review 49, 56.

Pindyck, R. S., and Rubinfeld, D. L. (1981), Econometric Models and Economic Forecasts, McGraw-Hill, New York.

Reiss, A. J., Jr. (1971), The Police and the Public, Yale Univ. Press, New Haven.

Rosett, A., and Cressey, D. R. (1976). Justice by Consent: Plea Bargains in the American Courthouse, Lippincott, Philadelphia.

Roy, M. (1977), "Some thoughts regarding the criminal justice system and wife-beating," in Battered Women: A Psychosociological Study of Domestic Violence (M. Roy, Ed.), Van Nostrand-Reinhold, New York.

Smith, D. A. (1984), "The organizational context of legal control," Criminology 22, 19.

Stanko, E. A. (1982), "The impact of victim assessment on prosecutors' screening decisions: the case of the New York County District Attorney's Office," Law and Society Review 16, 225.

Sudnow, D. (1964), "Normal crimes: sociological features of the penal code in a public defender office," Social Problems 12, 255.

Vera Institute of Justice (1977), Felony Arrests: Their Prosecution and Disposition in New York City's Courts, Vera Institute of Justice, New York.

Visher, C. A. (1983), "Gender, police arrest decisions, and notions of chivalry." Criminology 21, 5.

Weick, K. E. (1976), "Educational organizations as loosely coupled systems," Administrative Science Quarterly 21, 1.

Wheeler, S., Weisburd, D., and Bode, N. (1982), "Sentencing the white-collar offender: rhetoric and reality," American Sociological Review 47, 641.

Williams, K. M. (1976), "The effects of victim characteristics on the disposition of violent crimes," in Criminal Justice and the Victim (William F. MacDonald, Ed.), Sage, Beverly Hills, Calif.

Worden, R. E., and Pollitz, A. A. (1984), "Police arrests in domestic disturbances: a further look," Law and Society Review 18, 105. 